\title{
FORMAÇÃO DE PROFESSORES: APRENDIZAGENS (RE)CONSTRUÍDAS NO CURSO DE ESPECIALIZAÇÃO EM DOCÊNCIA NA EDUCAÇÃO INFANTIL
}

\author{
Celi Costa Silva Bahia \\ Universidade Federal do Pará - UFPA (Brasil) \\ celibahia@yahoo.com.br·https://orcid.org/0000-0002-3104-2647 \\ Marileia Pereira Trindade \\ Universidade Federal do Pará - UFPA. (Brasil) \\ marileiatrindade@gmail.com · https://orcid.org/0000-0003-3492-9611 \\ Solange Mochiutti \\ Universidade Federal do Pará - UFPA. (Brasil) \\ solymo@ufpa.br. https://orcid.org/0000-0002-5085-0260
}

\begin{abstract}
Resumo. As crianças pequenas apresentam singularidades próprias do tempo de vida em que se encontram, bem como no modo como aprendem e se desenvolvem. Assim, a educação destinada a elas apresenta especificidades que exigem do professor saberes específicos. Neste sentido, sólida formação teórico-prática é indispensável ao professor de Educação Infantil. $\mathrm{O}$ artigo apresenta parte dos resultados do projeto de pesquisa "Os impactos da política do MEC na formação de professores em nível de especialização: um estudo de caso na Unidade de Educação Infantil (UEI) Wilson Bahia. Objetiva-se analisar a experiência formativa no Curso de Especialização em Docência na Educação Infantil, ocorrido na Universidade Federal do Pará, e a relação dessa formação com a docência na creche. A pesquisa tem uma abordagem qualitativa e como metodologia de coleta de informações realizou-se a roda de conversa com professoras egressas do curso. A organização e análise das informações baseiam-se em técnicas da Análise de Conteúdo. Os resultados apontam que os fundamentos teóricos-metodológicos que permearam a formação no curso possibilitaram às professoras o exercício da reflexão de suas práticas pedagógicas e a (re)construção dos saberes sobre o trabalho docente na creche, bem como permitiu qualificar o fazer do docente universitário que atua na formação inicial de professores. Os dados revelam quão necessário é o diálogo entre universidade e instituição de Educação Infantil para a construção de saberes necessários à docência com bebês.
\end{abstract}

Palavras-chave: Bebê, creche, Educação Infantil, formação de professor.

\section{TEACHER TRAINING: LEARNING (RE)CONSTRUCTED IN THE CLASS OF SPECIALIZATION IN TEACHING IN EARLY CHILDHOOD EDUCATION}

\footnotetext{
Abstract. Young children have unique characteristics of the time they live in, as well as the way they learn and develop. Thus, education for them presents specificities that require specific knowledge from the teacher. In this sense, a solid theoretical-practical training is essential for the teacher of early childhood education. The article presents part of the results of the research project "The impacts of the MEC policy on teacher training at the level of specialization: a case study in the Child Education Unit (UEI) Wilson Bahia". It is intended to analyze the training experience in the Specialization Course in Teaching in Early Childhood Education, which took place at the Federal University of Pará, and the relation of that training with teaching in the nursery. The research has a qualitative approach and as a
} 
methodology for collecting information, the conversation was held with teachers who graduated from the course. The organization and analysis of the information are based on the techniques of content analysis. The results point out that the theoretical-methodological foundations that permeated the training in the course allow teachers to reflect on their pedagogical practices and (re) construct knowledge about teaching work in daycare, as well as to qualify the making of the university teacher who acts in the initial teacher training. The data reveal the necessary dialogue between the university and the institution of early childhood education for the construction of knowledge necessary for teaching with babies.

Keywords: Baby, day care center, early childhood education, teacher training.

\title{
FORMACIÓN DE PROFESORES: APRENDIZAJE (RE)CONSTRUIDAS EN EL CURSO DE ESPECIALIZACIÓN EN DOCENCIA EN LA EDUCACIÓN INFANTIL
}

\begin{abstract}
Resumem. Los niños pequeños presentan singularidades propias del tiempo de vida en que se encuentran, así como en el modo en que aprenden y se desarrollan. Así, la educación destinada a ellos presenta especificidades que exigen del profesor saberes específicos. En este sentido, una formación sólida teóricopráctica es indispensable para el profesor de educación infantil. El artículo presenta parte de los resultados del proyecto de investigación "Los impactos de la política del MEC en la formación de profesores a nivel de especialización: un estudio de caso en la Unidad de Educación Infantil (UEI) Wilson Bahia". Se pretende analizar la experiencia formativa en el Curso de Especialización en Docencia en la Educación Infantil, ocurrido en la Universidad Federal de Pará, y la relación de esa formación con la docencia en la guardería. La investigación tiene un abordaje cualitativo y como metodología de recolección de informaciones se realizó la rueda de conversación con profesoras egresadas del curso. La organización y el análisis de la información se basan en las técnicas de análisis de contenido. Los resultados apuntan que los fundamentos teóricos-metodológicos que permearon la formación en el curso posibilita a las profesoras el ejercicio de la reflexión de sus prácticas pedagógicas y la (re) construcción de los saberes sobre el trabajo docente en la guardería, así como permitió calificar el hacer del docente universitario que actúa en la formación inicial de profesores. Los datos revelan lo necesario que es el diálogo entre universidad e institución de educación infantil para la construcción de saberes necesarios para la docencia con bebés.
\end{abstract}

Palabras clave: Bebés, guardería, Educación Infantil, formación de profesor.

\section{Introdução}

$\mathrm{Na}$ contemporaneidade, o tema da formação inicial e continuada de professores tem sido pauta de discussão da política governamental e vem traduzindo-se em inúmeras ações destinadas à formação de professores das diferentes etapas de ensino. Essa discussão deve-se ao fato de as pesquisas demonstrarem que a formação do professor é uma das condições para elevar o nível da qualidade da educação oferecida às crianças do país. Compreender a relevância da formação docente no cenário nacional é fundamental, pois ela precisa ser de qualidade e capaz de responder às demandas enfrentadas pelo professor no cotidiano da escola.

A Educação Infantil, como primeira etapa da Educação Básica, requer muito investimento para consolidar índices de qualidade desejados, sendo que, nesse contexto, situa-se a formação dos professores que atuam nessa etapa de educação. Assim, nos últimos anos, o governo vem desenvolvendo programas de formação para professores que trabalham com crianças de zero a cinco anos de idade. Dentre estes, situa-se o 
Curso de Especialização em Docência na Educação Infantil como uma das ações da política governamental que visa, em última instância, imprimir qualidade na educação que vem sendo oferecida às crianças pequenas de nosso país.

Considerando o compromisso social da universidade pública, nos sentidos de formar professores para a Educação Básica e aperfeiçoar cada vez mais essa oferta, o presente texto apresenta parte dos resultados do projeto de pesquisa "Os impactos da política do MEC na formação de professores em nível de especialização: um estudo de caso na UEI Wilson Bahia", realizado no ano de 2016, com o objetivo de discutir a experiência formativa do Curso de Especialização em Docência na Educação Infantil desenvolvido na Universidade Federal do Pará (UFPA), além de analisar os entrelaços dessa experiência com a prática docente de professoras de creche.

A pesquisa foi realizada em uma Unidade de Educação Infantil (UEI) que trabalha exclusivamente com bebês e conta com o maior número de professoras egressas do curso, considerando-se a área metropolitana de Belém. Como metodologia para o levantamento das informações, realizou-se a pesquisa de campo, de natureza qualitativa, por meio de uma roda de conversa com professoras egressas do respectivo curso.

Inicialmente, o artigo situa a Educação Infantil no país, trazendo o debate sobre a formação de professores e a docência na creche; em seguida, apresenta o Curso de Especialização em Docência na Educação Infantil, destacando sua estrutura curricular; na sequência, discorre sobre o percurso metodológico utilizado na pesquisa, seguido pelos principais resultados encontrados; e finaliza com as considerações finais, apontando as contribuições do curso para os professores que dele participaram, mas também para os docentes que atuam na formação inicial e continuada de professores da Educação Infantil no interior da universidade.

\section{Formação de professores e a docência na creche}

O cenário da Educação Infantil brasileira nos últimos anos é marcado por inúmeras mudanças em decorrência da produção de conhecimento sobre a criança, de modo particular sobre seu processo de aprendizagem e desenvolvimento em ambientes coletivos, bem como em virtude das mudanças na legislação brasileira sobre a educação da criança pequena.

Na política pública brasileira, a criança é reconhecida como um sujeito histórico, de direitos, protagonista, cidadão. Possui direito à educação, desde zero ano de idade, em estabelecimentos educacionais cuja função é cuidar e educar de forma global e harmônica dela em seus aspectos físico, social, afetivo e cognitivo, de acordo com a Lei $\mathrm{n}^{\circ} 9.394$ (Brasil, 1996).

Sendo a criança um ser integral, cujas características físicas, sociais, culturais, emocionais, cognitivas se relacionam, sua educação deve contemplar essa articulação. Nesse âmbito, perpassa a defesa da associação entre o cuidado e a educação nas instituições de Educação Infantil, visto que:

tudo o que se faz em cuidado está transmitindo valores, estilos de relacionamento, formando a autoestima da criança, dando-lhe experiências e elementos para construir determinada visão de mundo, de si mesma e do outro. Ora, isso é, essencialmente, educação. Simultaneamente, avança-se na compreensão de que tudo o que se faz em educação é, na essência, um ato de cuidado, um olhar de zelo pelo bem-estar completo da criança, isto é, para que ela cresça sadia e seja feliz, o que implica se desenvolver física, 
social, emocional e intelectualmente. (Nunes, Corsino e Didonet, 2011, p. $13)$.

Mesmo com essa importante defesa, ainda é um desafio nas práticas cotidianas da educação de crianças a indissociabilidade entre educação e cuidado. Essa defesa "é resultado de um processo de mais de cem anos na sociedade brasileira, que ainda não chegou à completa aplicação de suas consequências na educação infantil"' (Nunes et al., 2011, p. 13).

$\mathrm{Na}$ atualidade, são visíveis as mudanças na política pública para a Educação Infantil. Contudo, essas mudanças não vêm traduzindo-se na qualificação da prática pedagógica dos professores que educam e cuidam de bebês e crianças pequenas em ambientes coletivos.

Uma possível explicação para o distanciamento entre os avanços conquistados e a prática pedagógica diz respeito à formação docente. Assim, destaca-se a necessidade de investimento na formação do professor como condição para a construção de práticas pedagógicas que atendam às especificidades da ação educativa com as crianças brasileiras menores de seis anos.

Embora se reconheça a necessidade de formação para a construção da profissionalidade ${ }^{i}$ do docente de bebês, a formação inicial não tem assegurado aos futuros educadores os saberes necessários ao exercício da docência com os pequeninos. Conforme Secanechia (2011), os alunos do curso de Pedagogia podem concluir sua formação inicial sem conhecer a realidade de creches e sem realizar atividades destinadas ao atendimento da criança de 0 a 3 anos, pois os conteúdos que lhes são oferecidos são, geralmente, dirigidos à docência na Pré-Escola e no Ensino Fundamental. Logo, o contato com ações de educação e cuidados realizadas com bebês e crianças pequenas em creche vem sendo secundarizado.

Nessa perspectiva, Cordão (2013) ressalta a necessidade de os cursos de Pedagogia oferecerem uma formação que favoreça aos futuros professores a compreensão do processo de ensino. Essa compreensão favoreceria a formulação de estratégias de ensino para se alcançar o aprendizado de todos os alunos, pois, no exercício da docência, é indispensável agir com intencionalidade educativa.

Entre a produção de conhecimentos sobre a formação de professores e o âmbito da atuação docente no cotidiano da Educação Infantil, existe uma relação complexa. Por um lado, tem-se uma vasta produção teórica que orienta a formação dos professores e, por outro, uma variedade de práticas docentes. Contudo, Filho e Filho (2011) alertam que não é possível separar a formação docente e a prática dos professores, pois ambas são revestidas de complexidade e são complementares entre si.

Lüdke e Boing (2012, p. 433) consideram que formar professores é uma tarefa exigente, dentre outros motivos, em função da complexidade do próprio magistério. Por essa razão, é necessário "considerar o trabalho efetivamente realizado pelos professores da educação básica como ponto central".

Nesse sentido, é importante que o professor se aproprie do saber historicamente construído a fim de superar práticas cristalizadas no cotidiano da escola, por meio da problematização destas e da reflexão sobre elas. Na Educação Infantil, a formação se articula com a busca de respostas para as demandas da prática, o que exige:

que se parta da prática pedagógica, problematizando-a, para buscar a sua instrumentalização por meio da reflexão crítica e que responda às demandas 
da prática para se chegar a uma educação como prática social refletida, o que resultará em mudanças reais nas concepções das profissionais. (Filho e Filho, 2011, p. 19).

Nessa perspectiva de formação docente, Goulart (2016) destaca que:

A formação docente se configura a partir de um movimento contínuo de ação e reflexão, este, que articula atos e atuações num âmbito de aproximações entre a experiência do cotidiano escolar e a concepção teórica. ( p. 709)

Nesse contexto, a universidade, particularmente nas Faculdades de Educação, precisa pautar a discussão sobre a docência na Educação Infantil. Esse debate se faz imperioso, pois poucos docentes se interessam por desenvolver pesquisas sobre essa temática, por causa da marginalização que a infância e essa etapa da Educação Básica sofreram ao longo da história. Consequentemente, ficam lacunas na formação do aluno de Pedagogia referentes ao exercício da docência nessa etapa.

Ainda que se reconheça a lacuna existente na formação inicial dos professores que trabalham na creche, sabe-se que a formação não tem a intenção de oferecer produtos acabados para serem consumidos na prática docente. Essa é a fase inicial de um longo processo de desenvolvimento profissional.

Nesse sentido, a formação continuada tem papel fundamental na construção de saberes necessários ao exercício da docência com crianças pequenas. Para tanto, é necessário um currículo que articule conteúdos e estratégias que visem à reflexão e à qualificação das práticas educativas com as crianças pequenas (Ferreira e Zurawski, 2011).

Tendo em vista o enfrentamento das lacunas existentes na formação do professor de Educação Infantil, o Ministério da Educação e Cultura (MEC) instituiu a Política Nacional de Formação dos Profissionais do Magistério da Educação Básica - Decreto $\mathrm{n}^{\mathrm{o}}$ 6.755, de 29 de janeiro de 2009. Como política permanente de estímulo à profissionalização docente, o decreto prevê, entre outras finalidades, a elevação da qualidade da formação docente. No âmbito dessa política está a oferta em nível nacional do Curso de Especialização em Docência na Educação Infantil.

\section{Curso de Especialização em Docência na Educação Infantil}

O Curso de Especialização em Docência na Educação Infantil, construído com a participação de professores pesquisadores de várias Universidades Federais, dentre estas a Universidade Federal do Pará, destinou-se a professores, coordenadores, diretores de creches e pré-escolas da rede pública e da rede privada sem fins lucrativos, conveniadas com o Poder Público, e equipes de Educação Infantil dos sistemas públicos de ensino. Ele tinha como objetivo central qualificar a prática docente dos profissionais da Educação Infantil.

Com vistas ao alcance dos objetivos propostos pelo curso, seu currículo foi organizado em três eixos articulados entre si: Eixo I: Fundamentos da Educação Infantil, consubstanciado pelas disciplinas Infâncias e crianças na cultura contemporânea e nas políticas de Educação Infantil: diretrizes nacionais e contextos municipais, e Aprendizagem e desenvolvimento na infância; Eixo II: Identidades, prática docente e pesquisa, estruturado com as disciplinas Metodologias de pesquisa e Educação Infantil, Seminários de pesquisa e Análise crítica da prática pedagógica 
(ACPP); Eixo III: Cotidiano e ação pedagógica, composto pelas disciplinas Currículo, proposta pedagógica, planejamento e organização e gestão do espaço, do tempo e das rotinas em creches e pré-escolas, Brinquedos e brincadeiras no cotidiano da Educação Infantil, Linguagem, oralidade e cultura escrita, Expressão e arte na infância, Natureza e cultura: conhecimentos e saberes, Linguagem matemática: conhecimentos e saberes (Universidade Federal do Pará/Instituto de Ciências da Educação, 2011).

Como se pode observar, o conjunto das disciplinas integrantes do currículo do curso estava voltado para o debate acerca da Educação Infantil. Com essa estrutura curricular, pretendia-se oferecer aos professores bases filosóficas, históricas, sociais e políticas que lhes possibilitassem refletir sobre o trabalho com e para as crianças, bem como planejá-lo, implementá-lo e avaliá-lo. Nesse sentido, o princípio orientador do currículo do curso foi a formação teórico-prática dos professores.

Sustentado na compreensão de que uma sólida formação teórico-prática é indispensável ao professor, o currículo do curso foi organizado para oportunizar a reflexão sobre a prática, por entendê-la como elemento estruturante na formação do docente. Nessa perspectiva, além do conjunto das disciplinas que compõem o currículo do curso, a disciplina Análise crítica da prática pedagógica, integrante (ACPP) do Eixo II, transversalizou esse currículo visando à sistematização, reflexão e produção de conhecimentos sobre a prática docente, o que resultou no trabalho monográfico apresentado ao final do curso.

Ainda que a prática tenha sido o ponto de partida da formação dos professores, isso não quer dizer que ela tenha sido restrita e esvaziada de conteúdos teóricos. Ao contrário, as bases teóricas foram fundamentais para a reflexão sobre a prática. A decisão de tomar a reflexão sobre ela como ponto de partida sustenta-se na compreensão de que, no processo formativo de professores, é importante "tomar a prática e a vida cotidiana como mecanismo de reflexão" (Filho e Filho, 2011, p. 5).

Assim como na disciplina ACPP, no processo de construção da monografia, o discente teve a oportunidade de planejar, repensar e replanejar o seu fazer pedagógico e isso, por sua vez, exigiu leitura, interpretação e análise crítica do contexto em que estão situados. Desse modo, os fundamentos teórico-práticos da formação dos cursistas subsidiaram reflexões sobre situações concretas, a produção de conhecimentos e a construção de soluções acerca das situações-problemas vivenciadas no cotidiano, possibilitando-lhes assim reinventar suas práticas educativas.

Como já mencionado anteriormente, sabe-se que o trabalho docente com bebês é uma tarefa complexa, o que torna a formação de professores que com eles trabalham também uma tarefa complexa. Por essa razão, decidiu-se investigar os reflexos do referido curso nas práticas educativas dos egressos do curso desenvolvido pela UFPA. Isso se faz necessário porque, para qualificar a formação dos professores de Educação Infantil, a universidade também precisa aprender sobre a docência nessa etapa, de modo particular com bebês. Para tanto, no ano de 2015, desenvolveu-se a pesquisa intitulada: "Os impactos da política do MEC na formação de professores em nível de especialização: um estudo de caso na UEI Wilson Bahia”.

\section{Método}

A pesquisa foi realizada na Unidade de Educação Infantil (UEI) Wilson Bahia. A escolha dessa unidade justifica-se pelo fato de que ela trabalha exclusivamente com 
bebês e nela se encontra o maior número de professoras egressas do curso, considerando-se a área metropolitana de Belém.

Participaram desse estudo quatro professoras egressas do Curso de Especialização em Docência na Educação Infantil que desenvolvem suas atividades profissionais na UEI Wilson Bahia. Todas elas possuem formação em Pedagogia. Para duas delas, o ingresso na Educação Infantil ocorreu no período de estágio extracurricular. As outras duas iniciaram essa experiência já como docentes, seja do quadro efetivo (via concurso público), seja do temporário. O tempo de inserção delas no trabalho com crianças, em geral, varia entre seis e dez anos. A experiência profissional das participantes é distinta. Três professoras trabalharam apenas em creche e uma trabalhou com creche e pré-escola.

Para a coleta de informações, utilizou-se uma roda de conversa. Essa escolha se deu, principalmente, por permitir que os participantes possam expressar suas impressões, opiniões, concepções e seus conceitos sobre o assunto, ao mesmo tempo em que permite trabalhar reflexivamente as manifestações apresentadas pelo outro, pelo grupo (Méllo et al., 2007).

A roda de conversa também possibilita interações, pois promove um espaço de diálogo, com a escuta de diferentes "falas" que ali se manifestam, caracterizando-se, assim, como um instrumento que favorece a compreensão de processos de construção de uma certa realidade vivenciada por um grupo específico. Portanto, a roda de conversa é uma técnica que:

permite compreender processos de construção da realidade por determinados grupos sociais, compreender práticas cotidianas, ações e reações a fatos e eventos, comportamentos e atitudes, constituindo-se uma técnica importante para o conhecimento das representações, percepções, crenças, hábitos, valores, restrições, preconceitos, linguagens e simbologias prevalentes no trato de uma dada questão por pessoas que partilham alguns traços em comum, relevantes para o estudo do problema visado... além de ajudar na obtenção de perspectivas diferentes sobre uma mesma questão, permite ideias partilhadas por pessoas no dia a dia e dos modos pelos quais os indivíduos são influenciados pelos outros. (Gatti, 2005, p. 11).

Para a realização da roda de conversa, as professoras foram convidadas previamente a participar de outra roda de conversa. Conforme o aceite, foi combinada a realização da atividade na Unidade Wilson Bahia, no horário de 12 às 14 horas.

Ao iniciar a roda, a pesquisadora esclareceu os objetivos do estudo e a forma de participação das professoras durante o diálogo, bem como apresentou os seguintes eixos orientadores da discussão: (a) as necessidades formativas das professoras e o Curso de Especialização em Docência na Educação Infantil; (b) as ideias das professoras sobre infância, aprendizagem e desenvolvimento e trabalho docente; e (c) a prática docente dos profissionais: transformações, necessidades e dificuldades a partir do curso. Dado o alcance dos objetivos do presente estudo, serão apresentadas apenas as análises referentes ao primeiro eixo.

Para se tratar as informações coletadas, foram utilizadas técnicas da Análise de Conteúdo na perspectiva de Bardin (2002). A análise de conteúdo corresponde a um conjunto de técnicas de análise das comunicações que utiliza procedimentos sistemáticos e objetivos de descrição do conteúdo das mensagens, dentre estes a categorização, compreendida como rubricas ou classes que reúnem um conjunto de 
elementos em um título genérico em razão dos caracteres comuns desses elementos, que podem ser ideias, elementos, expressões etc. (Bardin, 2002). Assim, após a transcrição dos diálogos estabelecidos na roda, procedeu-se à categorização das informações. Os relatos foram decompostos e, em seguida, recompostos nas seguintes categorias temáticas: (a) Aprendizagens e necessidades formativas sobre a docência na Educação Infantil; (b) Contribuições do curso: as aprendizagens sobre a docência.

Para se discutir a experiência formativa no Curso de Especialização em Docência na Educação Infantil e os entrelaços com as práticas das professoras, decidiuse, primeiramente, tornar visíveis suas ideias a respeito das próprias aprendizagens como docentes na Educação Infantil antes do curso e de suas necessidades formativas, bem como das contribuições deste no seu processo de (re)construção do trabalho que realizam com os pequeninos.

\section{Resultado e discussão}

\section{Aprendizagens e necessidades formativas sobre a docência na Educação Infantil}

Como já mencionado anteriormente, a docência na Educação Infantil reveste-se de especificidades e complexidade. Contudo, o currículo dos cursos de formação de professores não tem sido suficiente para o desenvolvimento de saberes necessários à docência na Educação Infantil. Por esse motivo, os professores dificilmente dispõem de fundamentação teórico-prática que lhes permita construir uma compreensão sobre a natureza do trabalho pedagógico na Educação Infantil.

Em decorrência, a aprendizagem sobre a docência encontra-se pautada em reprodução de práticas institucionalizadas, a partir da observação da prática de outra professora mais experiente, sem haver a reflexão sobre em que condições e de que maneira as crianças aprendem. A apropriação de uma prática docente nessa condição desenvolve um fazer docente espontaneísta, baseado no senso comum, que reproduz determinadas escolhas e prioridades na prática pedagógica, como se observa nas verbalizações das participantes:

Aprendi a trabalhar de forma escolarizante, era mesmo de usar caderno desde o maternal, escrever o nome, cobrir a ambientação do espaço, era para alfabetizar, ter alfabeto, números, cores. As crianças saiam alfabetizadas. (Prof. ${ }^{a} \mathrm{C}$ ).

Eu observava a prática das professoras que aqui já estavam (referindo-se à creche) e a minha ia na mesma direção, repetindo... como não entendia muito bem o que era o trabalho, eu fazia muitas atividades, cartazes, aí tinham vários, também várias produções, fazia colagem, fazia pintura, porque era uma necessidade pra sair daquela questão somente do cuidado, principalmente no berçário. (Prof. a A).

$\mathrm{Na}$ Educação Infantil eram aqueles trabalhinhos, era um modelo de escola. Eu achava que no berçário, quando o bebê começasse a falar, eu tinha que ensinar a contar: 1, 2, 3. A ler: a, e, i, o, u. Muito na ideia de preparação. (Prof. ${ }^{\mathrm{a}} \mathrm{B}$ ).

Os relatos das professoras permitem perceber que a aprendizagem da docência na Educação Infantil foi marcada por uma concepção de ensino pela via da transmissão de conhecimentos, em que o foco do trabalho é o produto, seja este por meio de 
atividades padronizadas, em que prevalece a ideia de que, para se aprender a ler e escrever, são necessários exercícios de repetição de letras e palavras, seja por meio de "trabalhinhos" com objetivo preparatório. Esse produto também ocupa prioridade na prática docente pela via de modelos prontos, acabados, trazidos pela professora definidos e definidores de ideias sociais padronizadas.

Tais práticas revelam uma concepção de Educação Infantil que tem como referência o modelo escolar, em que não se indaga sobre os modos próprios de a criança aprender. Entretanto, compreende-se que educar e ensinar nessa etapa da educação é colocar a criança na presença de elementos da cultura, de conhecimentos do patrimônio social e cultural, a fim de que ela se nutra desses elementos e construa a sua identidade intelectual e pessoal.

Além de vivenciarem aprendizagens docentes construídas a partir de práticas com foco no produto, as professoras foram formando-se em meio a incertezas, dúvidas, inseguranças, angústias, especialmente aquelas que trabalham no berçário:

Minha prática era marcada pela angústia, me angustiava muito porque eu não sabia o que fazer com os bebês... Como não se valorizavam as ações de cuidado, que tomava a maior parte do tempo, ficava a sensação que não se fazia nada, porque passava quase a tarde toda como se o momento fosse só de cuidar e não é só de cuidar. (Prof. ${ }^{a}$ B).

Eu percebia que havia alguma coisa que estava faltando, porque eu sentia uma necessidade dentro de mim, às vezes eu ficava muito agoniada... O que fazer, o que propor para as crianças. (Prof. ${ }^{a} \mathrm{~A}$ ).

As dúvidas relacionadas à natureza do trabalho docente na creche, a dificuldade de compreender o quanto as experiências de cuidado podem ser ricas e significativas no processo de aprendizagem e desenvolvimento dos pequeninos, bem como a singularidade que eles apresentam para aprender e se relacionar com o conhecimento impossibilitavam as professoras de perceber o quanto a sutileza da ação docente é própria do trabalho com bebês. Nesse sentido, é indispensável a presença atenta e disponível do adulto para compartilhar os conhecimentos produzidos e acumulados pela humanidade ao longo de sua história.

A reflexão sobre o processo de aprendizagem da docência na Educação Infantil precisa considerar o momento histórico de transição dessa etapa da educação a partir da década de 1990, caracterizada pela ruptura e (re)construção de práticas, tanto pela via dos documentos legais quanto pela produção de conhecimentos na área. Nesse novo contexto, uma questão importante diz respeito à especificidade da criança e à compreensão da natureza do trabalho docente nessa etapa de educação, como assinala Cordão (2013).

É perceptível, no entanto, que, apesar dos progressos alcançados legalmente por meio de documentos oficiais e leis ou mesmo pela produção de conhecimento na área, de um modo geral, ainda existe um distanciamento entre as conquistas legais e políticas e as práticas que são efetivadas no cotidiano das instituições. As verbalizações das docentes revelam as dificuldades no exercício da docência. Diante de suas incertezas e dúvidas, elas buscavam referência na prática de outra professora, que também estava cercada de dúvidas quanto às especificidades do trabalho com os pequenos em espaços educativos coletivos.

Em decorrência dessas experiências de aprendizagem na docência, as professoras tinham necessidades formativas, nem sempre percebidas por elas mesmas. 
Aliás, muitas dessas necessidades só foram notadas após o debate teórico-prático ocorrido no curso, em que elas passaram a perceber que, de fato, faltavam-lhes fundamentos para alicerçar a própria prática:

eu tinha necessidade de saber o que fazer, o que propor para aquelas crianças, principalmente no berçário. Então a minha necessidade era o currículo... de ter algo palpável. E não compreendendo bem o que era o trabalho com os bebês, que é a questão da sutilidade e das relações com as professoras, com os outros bebês e com o espaço, não tinha nada disso. (Prof. ${ }^{\mathrm{a}} \mathrm{A}$ ).

Minha necessidade era da prática... eu queria produzir, ter minhas ideias pra (sic) pensar as atividades para as crianças. Eu sentia necessidade de fundamentar a minha prática, porque eu conseguia fazer o que me diziam, eu queria fundamentação para essa prática. (Prof. ${ }^{a} \mathrm{C}$ ).

Eu era professora de uma turma de berçário e quanto menor as crianças, e quanto menos se percebe as respostas do bebê, mais difícil... naquela época eu tinha dificuldade de compreender aqueles bebês que estavam lá, então eu não sabia se o que eu estava fazendo estava certo ou errado... se ia dar resultado ou não. (Prof. ${ }^{\mathrm{a}} \mathrm{B}$ ).

As minhas necessidades partiram da minha graduação, eu fiz educação a distância... Quando cheguei aqui (referindo-se à creche), tudo era muito novo... quando cheguei na creche, eu pensei o que vou fazer com esses bebês? (Prof. ${ }^{\text {a }} \mathrm{D}$ ).

É possível perceber que as necessidades de fundamentar a prática estavam direcionadas para o que fazer, ou seja, para resolver problemas concretos circunscritos ao trabalho com os pequenos. Contudo, sabe-se que as respostas para as necessidades da prática só podem ser encontradas se alicerçadas na compreensão de quem é o bebê e do seu processo de aprendizagem e desenvolvimento, isso necessariamente precisa estar relacionado com a prática docente, razão pela qual um dos desafios dos cursos de formação é a articulação entre a teoria-prática. É nesse sentido que Nóvoa (2008, p. 8) destaca: “A formação dos professores continua hoje muito prisioneira de modelos tradicionais, de modelos teóricos muito formais, que dão pouca importância a essa prática e à sua reflexão".

As análises das verbalizações das professoras acerca das suas necessidades formativas apontam o quanto formar professores é uma tarefa exigente (Lüdke e Boing, 2012), pois, como indicam Filho e Filho (2011), a formação docente é revestida de complexidade e estabelece uma relação de complementariedade com a prática pedagógica. Assim, necessário se faz desenvolver processos formativos subsidiados por reflexões acerca da prática docente, as quais se fundamentam no conhecimento teórico, nos saberes acumulados sobre a educação, bem como na capacidade de saber mobilizálos em situações concretas no cotidiano escolar (Goulart, 2016).

Em se tratando da docência na Educação Infantil, essa exigência se acentua em virtude da complexidade e especificidade que se materializam nas ações cotidianas de cuidado e educação, que muitas vezes não são percebidas dentro da rotina diária, mas que são determinantes na caracterização do ser professora de bebês. Tais ações são marcadas pela sutileza, pois, de acordo com Tristão (2004), implicam o acolhimento à singularidade de cada bebê, que precisa ser conduzido pela promoção de relacionamentos intensos e prazerosos, mas também de confrontos - que também 
trazem consigo a possibilidade de trocas e de não consenso -, pelos olhares atentos, definidos pela curiosidade, pelo espanto, pelo questionamento, pela humildade do não saber e não predizer, pela possibilidade da descoberta conjunta, da experiência compartilhada.

Esse caminho não está pronto, portanto precisa ser construído a partir de uma sólida formação teórico-prática, para que os atos pedagógicos possam produzir significados para os pequenos, e para que as professoras, por sua vez, possam extrair sentido do que está sendo proporcionado a eles.

\section{Contribuições do curso: aprendizagens sobre a docência}

Para além das necessidades formativas, as participantes destacaram o quanto o curso contribuiu para a constituição da sua profissionalidade de professoras de bebê. Os fundamentos teóricos foram basilares para melhor compreenderem quem é esse ser e o seu modo singular de aprender, o que, por sua vez, possibilitou-lhes visualizar a especificidade do trabalho docente com esse público e, consequentemente, repensar suas práticas.

As falas a seguir demonstram a compreensão das professoras sobre quem é o bebê:

Para mim o bebê era um ser que precisava de proteção, até precisava do trabalho pedagógico, mas sem a clareza... hoje entendo que o bebê é um ser social que se desenvolve de modo diferente, dependendo das oportunidades, ele se desenvolve diferente. $\mathrm{O}$ desenvolvimento está relacionado às interações, ao meio em que a criança está, o que é propiciado favorece ou não o desenvolvimento dela. (Prof. ${ }^{a}$ A).

Não se tinha clareza de quem era o bebê, era mais um olhar para o bebê como ser de necessidade... Hoje eu consigo ver os bebês como alguém que tem potencial, alguém que está crescendo como ser completo, está crescendo, mas que não precisa apenas dos meus cuidados... Eu tinha muita ansiedade que todos fossem da mesma forma e hoje se entende que cada criança tem um tempo e aí isso é muito em função das leituras. (Prof. ${ }^{a}$ B).

Tais verbalizações levam a refletir sobre o quanto o curso lhes forneceu as bases necessárias para a compreensão do bebê como um ser que, além de ter necessidades, tem também potencialidades. Essa compreensão permitiu às professoras entenderem que este, como sujeito histórico e social, aprende e se desenvolve por meio das interações que estabelece nos diferentes contextos em que vive.

A partir de tal compreensão, as docentes destacam o quanto os bebês apresentam uma maneira singular no seu processo de aprender:

Eu não tinha clareza de como a criança desenvolvia a fala, a motricidade. Eu via que isso acontecia, mas eu não tinha clareza como isso acontecia e nem tampouco compreendia a minha participação nesse processo... hoje eu consigo perceber que em todos os momentos que eu me relaciono, que eu olho, que eu falo, que me disponho estar com ele, ele tá se desenvolvendo, naquele momento eu não tinha clareza disso. (Prof. ${ }^{a}$ B).

Eu lembro que eu aprendi uma coisa que eu nunca tinha pensado sobre isso. A gente ensina respeito para uma criança respeitando ela. Foi numa aula, aí eu passei a refletir, sobre algumas situações, algumas intervenções, a forma como estou intervindo. (Prof. ${ }^{\mathrm{a}} \mathrm{A}$ ). 
A percepção sobre como os bebês aprendem foi fundamental para as professoras compreenderem o quanto o trabalho docente com eles é marcado por especificidades:

Com os estudos e leituras no curso fui compreendendo o que fazer, o que propor para as crianças com mais tranquilidade... Lá no curso eu vi e aí eu pensei sobre a importância do espaço e aí eu pensei "Poxa aqui ainda não tá assim" e aí comecei a fazer inserções no espaço. (Prof. ${ }^{a} \mathrm{~A}$ ).

O curso foi me dando subsídios para entender sobre o trabalho... foi me dando consciência que quando eu tô intervindo, quando preparo o espaço, tudo o que eu for fazer, eu tô contribuindo com a construção daquela criança. (Prof. ${ }^{a} \mathrm{C}$ ).

Hoje tenho mais clareza do que fazer para auxiliar o processo de desenvolvimento do bebê, estar ao lado do bebê, compreender o bebê... hoje eu consigo ter a clareza que no momento de cuidado, se eu tenho maior atenção, maior sensibilidade, eu contribuo mais, se eu tenho menor atenção, eu contribuo menos. (Prof. ${ }^{\mathrm{a}} \mathrm{B}$ ).

A compreensão da maneira como a criança aprende, bem como do cuidar e educar como dimensões indissociáveis e inerentes ao trabalho docente na creche possibilitou às professoras superarem a ideia do ensino entendido como transmissão de conhecimentos, sem perderem de vista a necessidade de se preocupar com a aprendizagem da criança, o que é fundamental, pois muitas vezes, na ânsia de afastarem o antigo fantasma do processo de ensino, deixam de se preocupar com o aprender das crianças (Filho e Filho, 2011). Nesse sentido:

é patente a necessidade de resgatar o aprender para a educação infantil. Com o temor das práticas escolarizantes e de instrução, deixamos de falar na importância da aprendizagem para as crianças pequenas. Não é atribuição das professoras de educação infantil ensinar e transmitir (aliás, essa não deveria ser característica do trabalho de nenhum (a) docente). Contudo elas têm um papel fundamental, que defino como sutil, na aprendizagem das crianças. Este pode ser caracterizado como uma presença atenta e disponível a compartilhar os conhecimentos produzidos e acumulados pela humanidade ao longo da sua história. (Tristão, 2005, p. 29).

Assim, além de compreenderem que, na prática pedagógica com bebês, educação e cuidado são duas ações diversas, mas inseparáveis, as professoras passaram a ter consciência do quanto suas atitudes eram importantes no processo formativo dos bebês. Isso foi fundamental para repensar o trabalho docente, antes restrito ao cuidado com o corpo do bebê ou centrado no produto, agora voltado para a sua formação humana. Nesse sentido, concorda-se com a ideia de Filho e Filho (2011, p. 16) segundo os quais "somente uma formação consistente, teórica e reflexiva fornecerá subsídio para formar este profissional que deve agir como um profissional qualificado teoricamente para exercer uma prática consistente e positiva à formação humana das crianças".

O conjunto das verbalizações permite afirmar que, embora o curso não tenha dado sugestão do que fazer, de como agir com o bebê, de quais atividades lhe oportunizar (como as professoras esperavam), a partir da reflexão teórico-prática, possibilitou a compreensão sobre o que e o porquê fazer. Isso viabilizou a construção de conhecimentos sobre as diversas possibilidades de trabalho no espaço pedagógico.

Permitiu ainda o estranhamento de práticas que estavam ritualizadas no cotidiano da instituição, portanto naturalizadas e consideradas como "corretas". Isso 
oportunizou que as professoras revissem suas ideias, visualizando seus acertos e limites existentes no trabalho com os bebês, mas também reconstruindo ideias e ressignificando o trabalho docente.

Levou também à superação de práticas pautadas no senso comum e à compreensão da sutileza do processo educativo na Educação Infantil, o qual ocorre por meio das ações de cuidado e educação de modo indissociável. As ações de cuidado, que tomam a maior parte do tempo e que eram vistas como menores pelas docentes, ao oportunizarem diversas interações entre o bebê e o adulto, transformaram-se em experiências significativas no processo de constituição daquele.

Em síntese, pode-se afirmar que, a partir de toda essa compreensão, as professoras tiveram a oportunidade de ampliar suas ideias acerca do que é ser docente de criança pequena, tarefa essa extraordinariamente difícil, que exige muito conhecimento, mas que muitos ainda julgam ser fácil. Desse modo, concorda-se com Lüdke e Boing (2012, p. 433) quando assim se referem à formação de professores: "é preciso ultrapassar a aparente evidência de uma atividade de fácil execução, encarregada de ensinar coisas básicas, que são de domínio público, que todo mundo sabe, como ler, escrever e contar".

Concorda-se ainda com Cordão (2013, p. 187) quando este ressalta:

a necessidade do professor de educação infantil de compreender sua função de ensinar e promover o desenvolvimento infantil, de compreender a necessidade de ações planejadas e intencionais em todos os momentos de contato com as crianças. Um professor que tenha compreensão teórica e fundamente suas ações.

Para finalizar, pode-se afirmar que a proposta do curso de articular teoria e prática foi profícua para a formação das professoras egressas do curso.

A reflexão sobre a prática permitiu a produção de conhecimentos para responder às demandas do trabalho docente na creche. Entretanto, não se pode deixar de mencionar que o silenciamento que marcou a Educação Infantil no estado do Pará, e consequentemente a formação dos professores dessa etapa da Educação Básica, e o fato de que muitos professores estavam afastados dos bancos escolares há bastante tempo dificultaram o desempenho de muitos professores/alunos que ingressaram no curso de especialização. Eles apresentavam limitações na escrita e na compreensão textual, bem como pouca experiência acadêmica, além de uma visão equivocada e desatualizada de Educação Infantil, o que exigiu grande esforço dos professores/alunos e dos docentes para que os objetivos do curso fossem alcançados.

Portanto, registra-se que o processo de reflexão sobre a prática exigiu esforço dos professores/alunos e docentes. Esse processo foi marcado por resistência, medo, insegurança, mas também por ansiedade, motivação e desejo por parte dos primeiros. Para os docentes, representou um exercício, pois, apesar da experiência que possuem com orientação acadêmica, a pesquisa caracterizada pela reflexão sobre a prática colocou-os diante da necessidade de construir com os envolvidos novas aprendizagens, tanto no processo metodológico, como também na docência na Educação Infantil.

\section{Considerações finais}


A partir da análise dos dados da pesquisa, foi possível constatar o quanto a experiência formativa no Curso de Especialização em Docência na Educação Infantil desenvolvido na UFPA foi significativa para as professoras da Unidade Wilson Bahia, seja em virtude do acesso ao saber produzido na área da Educação Infantil, seja em virtude da possibilidade de refletirem sobre sua prática, mas também em função da possibilidade de produzirem conhecimentos necessários ao fazer pedagógico na creche. Desse modo, o conhecimento sobre o bebê e sua singularidade de aprendizagem foi formativo para as docentes, o que muito contribuiu para o processo de desconstrução e (re)construção do trabalho que realizam no espaço educativo.

As mudanças no fazer pedagógico identificadas pelas próprias professoras revelam o quanto a prática cotidiana, como objeto de reflexão na formação profissional, contribui para uma atitude reflexiva, o que pode ser considerado o maior legado do curso em questão. Portanto, ainda que, pela metodologia utilizada, a pesquisa não tenha fornecido informações suficientes para se afirmar que a formação contribuiu para mudanças efetivas na prática docente, pode-se dizer que as participantes passaram a compreender que, para que isso aconteça, a reflexão é indispensável, mas precisa se fundamentar no saber sobre como aprendem os bebês.

Por fim, no âmbito da universidade, o trabalho com a formação continuada de professores de Educação Infantil é importante para qualificar o fazer do docente que atua na formação inicial de professores que irão trabalhar nessa etapa. Portanto, entende-se que a universidade precisa se abrir para dialogar com aqueles que estão no cotidiano das instituições de Educação Infantil, pois ainda muito se tem a aprender sobre o trabalho docente na creche.

\section{Referências}

Bardin, L. (2002). Análise de conteúdo. (3. ed.). Lisboa: Edições 70.

Brasil. (1996). Lei $n^{\circ}$ 9.394, de 20 de dezembro de 1996. Estabelece as Diretrizes e Bases da Educação Nacional. Brasília: Casa Civil da Presidência da República. Retrieved from http://www.planalto.gov.br/ccivil_03/Leis/L9394.htm.

Brasil. (2009). Portaria $\mathrm{n}^{\circ} 1.129$, de 27 de novembro de 2009. Constitui a Rede Nacional de Formação Continuada dos Profissionais da Educação Básica. Diário Oficial da União, Brasília, 30 novembro 2009.

Brasil. (2009). Decreto $\mathrm{N}^{\circ}$ 6.755, de 29 de janeiro de 2009. Institui a Política Nacional de Formação de Profissionais do Magistério da Educação Básica, disciplina a atuação da Coordenação de Aperfeiçoamento de Pessoal de Nível Superior CAPES no fomento a programas de formação inicial e continuada, e dá outras providências. Diário Oficial da União, Brasília, 30 de janeiro de 2009.

Cordão, T. S. R. (2013). Necessidades formativas de professores de crianças de zero a três anos de idade. Dissertação de Mestrado, Centro de Ciências Sociais Aplicada, Pontifícia Universidade Católica, Campinas, SP, Brasil.

Ferreira, M. V. e Zurawski, M. P. (2011). Formação de professores e currículo integrado. Revista Educação Infantil, 2(num. esp.), 30-37.

Filho, A. J. M. e Filho, L. J. M. (2011). Da formação de professores à atuação docente na Educação Infantil: reflexões à luz da teoria histórico-social. Revista Percurso, 
12(1), 118-138. $\quad$ Retrived from http://www.periodicos.udesc.br/index.php/percursos/article/view/2224.

Gatti, B. A. (2005). Grupo focal na pesquisa em ciências sociais e humanas. Brasília: Líber Livro, Editora. Série Pesquisa em Educação.

Goulart, I. C. V. (2016). Linguagem, dialogicidade e docência: o processo de formação em atos. Revista. Diálogo Educativo., 16(49), 705-726.

Lüdke, M. e Boing, L. A. (2012). Do trabalho à formação de professores. Revista Cadernos de Pesquisa, 42(146), 428-451. doi: v.42 n.146 p.428-451 maio/ago.

Méllo, R. P. et al. (2007). Construcionismo, práticas discursivas e possibilidades de pesquisa. Psicologia e Sociedade, 19(3), 26-32.

Nóvoa, A. (2008). Nada substitui o bom professor. Palestra proferida em São Paulo, a convite do Sinpro-SP. Retrieved from http://www.sinpro.org.br/noticias.asp?id_noticia=639.

Nunes, M. F. R., Corsino, P. e Didonet, V. (2011). Educação Infantil no Brasil: primeira etapa da educação básica. Brasília: UNESCO, Ministério da Educação/Secretaria de Educação Básica, Fundação Orsa.

Oliveira-Formosinho, J. e Formosinho, J. (2002). A formação em contexto: a perspectiva da Associação Criança. In J. Oliveira-Formosinho e T. Kishimoto (Orgs.). Formação em contexto: uma estratégia de integração. (1-40). São Paulo: Pioneira Thomson Learning.

Secanechia, L. P. Q. (2011). Uma interpretação à luz da ideologia discursiva sobre bebês e a creche captada em cursos de Pedagogia da cidade de São Paulo. Dissertação de Mestrado, Faculdade de Psicologia, Pontifícia Universidade Católica, São Paulo, SP, Brasil.

Tristão, F. C. D. (2005). A sutil complexidade das práticas pedagógicas com bebês. In A. J. M. Filho (Org.). Infância plural: crianças do nosso tempo. (27-58). Porto Alegre: Mediação.

Tristão, F. C. D. (2004). Ser Professora de Bebês: um estudo de caso em uma creche conveniada. Dissertação de Mestrado, Centro de Ciências da Educação, Universidade Federal de Santa Catarina, Florianópolis, SC, Brasil.

Universidade Federal do Pará (2011). Projeto Básico do Curso de Especialização em Docência na Educação Infantil. Belém: UFPA.

\footnotetext{
${ }^{\text {i }}$ De acordo com Oliveira-Formosinho e Formosinho (2002), o termo profissionalidade diz respeito ao crescimento em especificidade, racionalidade e eficácia dos conhecimentos, das competências, dos sentimentos e das disposições para aprender ligadas ao exercício profissional dos educadores de infância.
} 
Data de recepção: 10/11/2018

Data de revisão: 05/06/2019

Data do aceite: 27/06/2019 